\title{
Year Book of Critical Care Medicine 1990
}

Edited by M. C. Rogers and J. E. PARriL

Year Book Medical Publishers, Inc., Chicago, 1990.

The material in this annual reviews literature published up to July 1989 and as such is already somewhat dated, a direct consequence of the rapidity at which the field of critical care medicine is advancing. For the clinician with an interest in resuscitation this is a useful volume to be dipped into.

Each paper selected is summarised and has an editorial review appended. Some of these comments obviously reflect the opinions of the reviewer and this is some- $\overrightarrow{0}$ times quite noticeable.

The series can be recommended for those clinicians in Accident \& Emergency who $\vec{D}_{\overparen{D}}$ like to keep abreast of current thoughts in critical care medicine and resuscitation.

\section{P. NIGHTINGALE}

\section{Intensive Care Manual}

Edited by T. E. Oн

Butterworths, Sydney, 1990, 700 pp.

It is now 5 years since the second edition of this manual was published and it ha grown appreciably since then, in line with the tremendous advances in intensive care medicine which are occuring. The organizaion of the book remains the same with short chapters giving practical advice followed by selected references. This format works well for those people seeking help and advice in a lucid and concise format, but deliberately falls short of an all-encompassing reference book. Virtually $\stackrel{\square}{\square}$ all the authors are from Australia and this shows in chapters such as those dealing $\vec{\circ}$ with organization in the ICU and on envenomation. However the text is easily 3 assimilated by the U.K. reader.

In summary, a readable yet comprehensive introduction to intensive care which will find a wide readership amongst both medical and nursing staff. Recommended.

P. NIGHTINGALE

\section{Anesthesia in Emergency Medicine}

Edited by G. S. VANSTRUM

Little Brown \& Co., Boston, 1989.

This is a new book in the burgeoning field of publications devoted to emergency medicine but it has however managed to find a very useful niche. In just over 400 